\title{
Preferences and Practices of U.S. Ophthalmology Residency Program Directors Regarding Post- interview Communication with Residency Applicants
}

\author{
Allison J. Chen, MD, MPH ${ }^{1}$ Elaine M. Tran²,3,4 \\ Paul B. Greenberg, MD, $\mathrm{MPH}^{2,3}$

\footnotetext{
${ }^{1}$ Department of Medicine, Roger Williams Medical Center, Boston University, Providence, Rhode Island

2 Section of Ophthalmology, Providence VA Medical Center, Providence, Rhode Island

${ }^{3}$ Division of Ophthalmology, Brown University, Alpert Medical

School, Providence, Rhode Island

${ }^{4}$ Program in Liberal Medical Education, Brown University,

Providence, Rhode Island

${ }^{5}$ Brown School of Public Health, Brown University, Providence, Rhode Island

${ }^{6}$ Department of Quantitative Health Sciences, University of Massachusetts Medical School, Worcester, Massachusetts

7 Departments of Ophthalmology and Public Health Sciences,
} \\ Penn State College of Medicine, Hershey, Pennsylvania
}

Melissa A. Clark, $\mathrm{PhD}^{5,6}$ Ingrid U. Scott, MD, $\mathrm{MPH}^{7}$

Journal of Academic Ophthalmology 2018;10:e43-e47.

\author{
Address for correspondence Paul B. Greenberg, MD, MPH, Division of \\ Ophthalmology, Brown University, Coro Center West, One Hoppin \\ Street, Suite 200, Providence, RI 02903 \\ (e-mail: paul_greenberg@brown.edu).
}

\begin{abstract}
Keywords

- residents

- graduate medical education

- interview

- program director

Importance Little is known about the perspectives and practices of U.S. ophthalmology residency program directors (PDs) regarding communication between PDs and applicants during the post-interview residency match period.

Objective To investigate the preferences and practices of ophthalmology residency PDs regarding post-interview communication between PDs and residency applicants during the residency match period.

Design and Setting Web-based anonymous survey.

Participants Directors of ophthalmology residency programs accredited by the Accreditation Council for Graduate Medical Education.

Results The response rate was $64 \%(74 / 116)$. The majority $(75 \% ; 55 / 73)$ of PDs preferred that PDs and residency applicants not communicate during the post-interview period; the main reasons were that such communication was not ethical and not productive. In addition, 62\% (46/74) of PDs believed that the Ophthalmology Matching Program should institute a policy of no post-interview communication between applicants and faculty during the residency match period.

Conclusion and Relevance The majority of U.S. ophthalmology residency PDs favor instituting a policy of no post-interview communication between applicants and faculty during the residency match period.
\end{abstract}

received

November 22, 2017 accepted after revision March 6, 2018
DOI https://doi.org/

10.1055/s-0038-1641608. ISSN 2475-4757.
Copyright $\odot 2018$ by Thieme Medical Publishers, Inc., 333 Seventh Avenue, New York, NY 10001, USA. Tel: +1(212) 584-4662.
License terms

(c) (1) $\ominus$ (\$) 
Post-interview communication between applicants and residency program directors (PDs) is time-consuming and can lead to mismatched expectations because residency applicants may interpret positive language from PDs as a promise to be ranked to match. ${ }^{1}$ In addition, PDs are left with the difficult task of interpreting and responding to messages from applicants. In light of these challenges, some specialties have adopted policies that discourage or prohibit routine "thank you" notes or emails from interviewed applicants

\section{(-Supplementary Table S1).}

Currently, the Ophthalmology Matching Program (OMP) has no policy regarding post-interview communication between ophthalmology residency program faculty and residency applicants. The Association of University Professors of Ophthalmology (AUPO) specifies that programs should not initiate contact with applicants until the match is completed, but has no official policy with regard to communications initiated by applicants. The paucity of guidelines on post-interview communication may result in inconsistencies in communication practices that expose the ranking process to unintended factors. For instance, applicants and/or faculty may be misled by communications that exaggerate interest from the other party. Despite the potential impact of post-interview communication on match outcomes, little is known about its use and influence on PD and applicant ranking behaviors. This study investigated the preferences and practices of U.S. ophthalmology residency PDs regarding post-interview communication during the residency match period and the impact of such communication on PD ranking of applicants.

\section{Methods}

The Brown University Institutional Review Board granted an exemption for the study. We administered an anonymous survey to all 116 U.S. ophthalmology residency PDs on current practices and preferences regarding post-interview communication during the application cycle. To our knowledge, there have not been any validated or previously used surveys on PD preferences regarding post-interview communication. Hence, the authors designed the survey instrument and then revised it based on input from two experienced ophthalmology PDs. The survey instrument (-Table 1) was administered using online survey software (Qualtrics, Provo, UT) licensed to Brown University.

Using publicly available email addresses from the American Medical Association's Residency and Fellowship Database Web site, FREIDA Online, we emailed the survey, along with a brief description of the study and its purpose, to all U.S. ophthalmology residency PDs. ${ }^{2}$ During the same week, we mailed a letter with the survey link along with a $\$ 1$ incentive to all the U.S. ophthalmology residency PDs. Weekly reminder emails were sent to nonresponders. After the third reminder email, nonresponders received two phone call reminders, spaced approximately 1 week apart. The survey was closed after 6 weeks. Identities of the responders were dissociated from their answers to the survey. Nonresponders were tracked, but this information was not linked to any individual responses. To assess for potential nonresponse bias, each program was categorized into one of four geographic locations (Northeast, Midwest, South, West) ${ }^{3}$ and into one of three program sizes (6-11 residents, $12-14$, and $15+),{ }^{4}$ and these characteristics were compared between the respondent and nonrespondent groups. Data were analyzed using descriptive statistics.

\section{Results}

The response rate was 64\% (74/116). Programs from the Northeast comprised 21\% of respondents, Midwest 26\%, South $36 \%$, and West $17 \%$. Thirty-eight percent of programs had 6 to 11 residents, $30 \%$ had 12 to 14 residents, and $32 \%$ had 15 or more residents. There was no difference in the distribution of geographic location $\left(\chi^{2}=3.05, p=0.38\right)$ or size of program $\left(\chi^{2}=0.62, p=0.73\right)$ between respondents and nonrespondents.

The results of the survey are summarized in - Table 1. The majority (75\%; 55/73) of PDs preferred no post-interview communication during the residency match period with the main reasons being that such communication is not ethical and not productive. The PDs indicated that, if they were to receive post-interview communication from an applicant, they would prefer that the applicant communicate why the program is a good fit for the applicant (34\%; 25/74), why the applicant is a good fit for the program $(31 \% ; 23 / 74)$, if the applicant plans to rank the program first (12\%; 9/74), and any program-specific questions $(5.4 \% ; 4 / 74)$.

Regarding post-interview communication and its potential effect on rank status, 21\% (16/74) of PDs stated that in at least one instance, post-interview communication changed the ranking status of an applicant. The majority $(71 \% ; 53 / 74)$ of PDs reported having been misled in post-interview communication(s) regarding applicant ranking of the program, and $60 \%$ (45/74) of PDs reported at least one instance in which an applicant falsely communicated that he/she would rank the PD's program first.

Two-thirds (49/74) of PDs were concerned that not responding to an applicant's query would give the impression of a lack of interest in the applicant, and nearly half (49\%; 36/74) of PDs found it challenging to formulate responses that did not mislead an applicant regarding his or her rank status.

While 34\% (25/74) of PDs reported that post-interview communication helps rank applicants, 62\% (46/74) of PDs indicated that the OMP should institute a policy of no postinterview communication between applicants and faculty, except for logistical questions directed from the applicant to the program coordinator.

\section{Discussion}

Results of this survey suggest that most PDs prefer no postinterview communication between residency applicants and program faculty during the residency match period.

The PDs had several reasons for avoiding post-interview communication. They believed it was time-consuming and neither ethical nor productive. In addition, nearly half of PDs 
Table 1 Post-interview communication survey results $(N=74)$

\begin{tabular}{|c|c|}
\hline Question & No. (\%) of program directors \\
\hline $\begin{array}{l}\text { Which statement best describes your preferences about applicants and program directors } \\
\text { communicating during the post-interview period? }\end{array}$ & $(N=73)$ \\
\hline $\begin{array}{l}\text { I prefer that applicants and program directors communicate during the post-interview } \\
\text { period }\end{array}$ & $18(25 \%)$ \\
\hline $\begin{array}{l}\text { I prefer that applicants and program directors do not communicate during the } \\
\text { post-interview period }\end{array}$ & $55(75 \%)$ \\
\hline $\begin{array}{l}\text { If response } 2 \text { is selected: Please select all statements about why you do not prefer } \\
\text { applicants and program directors to communicate during the post-interview period: }\end{array}$ & $(N=55)$ \\
\hline Communication in the post-interview period takes too much time & $19(35 \%)$ \\
\hline Communication in the post-interview period is not ethical & $31(56 \%)$ \\
\hline Communication in the post-interview period is not productive & $31(56 \%)$ \\
\hline $\begin{array}{l}\text { There are other reasons I do not prefer post-interview communication: } \\
\text { Summary of responses: Unethical/misleading (8), Does not affect ranking (3), } \\
\text { Blank response (3) }\end{array}$ & $14(25 \%)$ \\
\hline $\begin{array}{l}\text { If applicants contact you during the post-interview period, what do you like this } \\
\text { communication to contain? (check all that apply): }\end{array}$ & $(N=74)$ \\
\hline Reasons why the applicant thinks this program is a good fit for them & $25(34 \%)$ \\
\hline Reasons why the applicant is a particularly good fit for the program & $23(31 \%)$ \\
\hline If they are ranking my program no. 1 & $9(12 \%)$ \\
\hline $\begin{array}{l}\text { Other (specify): } \\
\text { Summary of responses: Program-specific questions (4), Thank you (2), Other (1): } \\
\text { Applicant expectations }\end{array}$ & $8(11 \%)$ \\
\hline $\begin{array}{l}\text { None of the above; I do not want applicants to contact me during the } \\
\text { post-interview period }\end{array}$ & $42(57 \%)$ \\
\hline $\begin{array}{l}\text { If applicants contact you during the post-interview period, when do you prefer this } \\
\text { communication to be sent? }\end{array}$ & $(N=74)$ \\
\hline Within the first 2 days after the interview & $2(2.7 \%)$ \\
\hline Within the first week after the interview & $15(20 \%)$ \\
\hline Before winter holidays & $12(16 \%)$ \\
\hline Other (specify) & $3(4.1 \%)$ \\
\hline $\begin{array}{l}\text { None of the above; I do not want applicants to contact me during } \\
\text { the post-interview period }\end{array}$ & $42(57 \%)$ \\
\hline $\begin{array}{l}\text { Has post-interview communication with an applicant ever made you } \\
\text { rank an applicant higher? }\end{array}$ & $(N=74)$ \\
\hline Yes & $16(22 \%)$ \\
\hline No & $43(58 \%)$ \\
\hline I have never communicated with an applicant during the post-interview period & $15(20 \%)$ \\
\hline If yes: What has made you rank an applicant higher? & $(N=16)$ \\
\hline \multicolumn{2}{|l|}{$\begin{array}{l}\text { Summary of responses: Genuine interest (7), Location restriction (4), Other (5): } \\
\text { additional positive information, potential impact on program }\end{array}$} \\
\hline $\begin{array}{l}\text { Has post-interview communication with an applicant ever made you } \\
\text { rank an applicant lower? }\end{array}$ & $(N=74)$ \\
\hline Yes & $15(20 \%)$ \\
\hline No & $45(61 \%)$ \\
\hline I have never communicated with an applicant during the post-interview period & $14(19 \%)$ \\
\hline If yes: What has made you rank an applicant lower? & $(N=15)$ \\
\hline $\begin{array}{l}\text { Summary of responses: Too much post-interview contact/aggressive (4), Tone of } \\
\text { correspondence (4), Neediness/begging ( } 2 \text { ), Other (5): Additional negative } \\
\text { information, confirmed interview concerns }\end{array}$ & \\
\hline
\end{tabular}


Table 1 (Continued)

\begin{tabular}{|c|c|c|}
\hline \multicolumn{2}{|l|}{ Question } & No. (\%) of program directors \\
\hline \multicolumn{2}{|c|}{$\begin{array}{l}\text { Have you ever been misled by applicant communications regarding where the applicant } \\
\text { was planning to rank your program? }\end{array}$} & $(N=74)$ \\
\hline \multicolumn{2}{|c|}{ Yes } & $53(72 \%)$ \\
\hline \multicolumn{2}{|l|}{ No } & $21(28 \%)$ \\
\hline \multicolumn{2}{|c|}{$\begin{array}{l}\text { Have you had at least one instance where an applicant communicated that he/she would rank } \\
\text { your program no. } 1 \text { when he/she did not? }\end{array}$} & $(N=74)$ \\
\hline \multicolumn{2}{|c|}{ Yes } & $45(61 \%)$ \\
\hline \multicolumn{2}{|l|}{ No } & $29(39 \%)$ \\
\hline \multicolumn{2}{|c|}{$\begin{array}{l}\text { Do you think communication between applicants and program directors in the } \\
\text { post-interview period can help rank applicants? }\end{array}$} & $(N=74)$ \\
\hline \multicolumn{2}{|c|}{ Yes } & $25(34 \%)$ \\
\hline \multicolumn{2}{|l|}{ No } & $35(47 \%)$ \\
\hline \multicolumn{2}{|l|}{ Don't know } & $14(19 \%)$ \\
\hline \multicolumn{2}{|c|}{$\begin{array}{l}\text { If applicants communicate with you during the post-interview period, do you reach out } \\
\text { specifically to those who are highly ranked? }\end{array}$} & $(N=74)$ \\
\hline \multicolumn{2}{|c|}{$\begin{array}{l}\text { Yes, we reach out to those who are ranked to match (those ranked in the number of spots } \\
\text { that are available in my residency program) }\end{array}$} & $1(1.4 \%)$ \\
\hline \multicolumn{2}{|c|}{$\begin{array}{l}\text { Yes, we reach out to those who are ranked within the number of spots that I historically } \\
\text { matched students (but greater than the number of residency spots available) }\end{array}$} & $2(2.7 \%)$ \\
\hline \multicolumn{2}{|c|}{$\begin{array}{l}\text { No, we respond to most or all applicants who communicate with us, regardless of if } \\
\text { they are ranked highly or not }\end{array}$} & $32(43 \%)$ \\
\hline \multicolumn{2}{|c|}{ No, we do not reach out to applicants } & $38(52 \%)$ \\
\hline \multicolumn{2}{|l|}{ Other } & $1(1.4 \%)$ \\
\hline $\begin{array}{l}\text { PD opinions on current and future } \\
\text { communication practices }(N=74)^{\mathrm{a}}\end{array}$ & $\begin{array}{l}\text { \% of PDs who "Agree" or } \\
\text { "Completely Agree" with } \\
\text { statement (no.) }\end{array}$ & $\begin{array}{l}\text { \% of PDs who "Disagree" } \\
\text { or "Completely Disagree" } \\
\text { with statement (no.) }\end{array}$ \\
\hline $\begin{array}{l}\text { The current level of post-interview communication } \\
\text { is excessive }\end{array}$ & $47 \%(35)$ & $18 \%(13)$ \\
\hline $\begin{array}{l}\text { If I do not respond to an applicant communication, } \\
\text { it may send a false message that I am uninterested } \\
\text { in them }\end{array}$ & $66 \%(49)$ & $9 \%(7)$ \\
\hline $\begin{array}{l}\text { I find it difficult to respond in an appropriate } \\
\text { manner to avoid misleading an applicant regarding } \\
\text { their rank status }\end{array}$ & $49 \%(36)$ & $32 \%(24)$ \\
\hline $\begin{array}{l}\text { The current post-interview communication system } \\
\text { is ethical }\end{array}$ & $26 \%(19)$ & $32 \%(24)$ \\
\hline $\begin{array}{l}\text { Aside from logistical questions directed to the } \\
\text { program coordinator, the Ophthalmology Match- } \\
\text { ing Program (OMP) should institute a policy of no } \\
\text { post-interview communication between applicants } \\
\text { and faculty }\end{array}$ & $62 \%(46)$ & $22 \%(16)$ \\
\hline
\end{tabular}

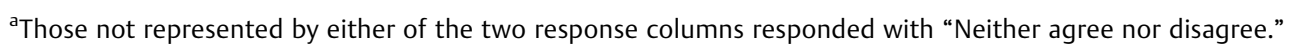

reported difficulty in responding to post-interview communication in an appropriate manner. Equally important, PDs often have been misled by applicant communications, including instances where applicants falsely communicated that they would rank the PD's program first. This is an important concern and consistent with other studies: 52\% of PDs from multiple specialties reported that, at least once a year, one or more applicants falsely claimed they were ranking their program number first. ${ }^{1}$ Similarly, several applicant surveys have shown that applicants often deliberately exaggerate their interest in training programs. ${ }^{5-7}$

Post-interview communication may also impact residency applicants. First, our findings suggest that applicants may be ranked higher or lower based on post-interview communication; although an applicant's expressed interest, location preference, and additional positive information can positively impact an applicant's rank, too much post-interview contact and perceived aggressiveness or neediness may 
have the opposite effect. Second, residency applicants often alter their rank order list based on communications with programs, ${ }^{5}$ including raising the rank of programs that applicants perceive show higher interest in them in the post-interview period. ${ }^{6}$ Complicating these trends, up to one-third of surveyed applicants from multiple specialties reported being misled by residency program leadership in post-interview communication. ${ }^{1}$

The AUPO has several options to address issues surrounding post-interview communication. Following the example of the American Council of Academic Plastic Surgeons, ${ }^{8}$ the simplest option would be to institute a policy of no postinterview communication between applicants and faculty (not including administrative queries directed to the program coordinator) during the match period. By eliminating the temptation for abuse and mistrust in post-interview communication, this approach would help level the ranking playing field. Our survey suggests that $62 \%$ of ophthalmology PDs favor this approach. As demonstrated by the Association of Program Directors in Internal Medicine (APDIM), another option would be to design specific guidelines on what may be included in post-interview communication. The APDIM recommends that programs refrain from sending routine "thank you" messages to applicants after the interview period, limit communications to factual pragmatic information sent to all applicants, and identify an approved contact who will be the sole communicator with applicants. ${ }^{9}$

This study is limited by potential response bias. PDs may have been more inclined to participate if they have had a prior experience with post-interview communication that strongly impacted their match results. However, the $63.8 \%$ response rate achieved in this study exceeds that of recent ophthalmology PD surveys (33-51\%). ${ }^{10,11}$ Furthermore, there was no significant difference between respondents and nonrespondents with respect to program geographic location or size.

In summary, many U.S. ophthalmology residency PDs would welcome an official policy from the AUPO regarding post-interview communication between applicants and programs during the match period. The experiences of plastic surgery and internal medicine demonstrate that national organizations representing academic ophthalmology and residency applicants can work together to achieve this goal.

Financial Support

None.
Conflicts of Interest

None declared.

Disclaimer

The views expressed in this article are those of the authors and do not necessarily reflect the position or policy of the Department of Veterans Affairs or the U.S. government.

\section{Acknowledgments}

We thank Maggie Chung, MD, for her assistance with the preparation of the mailed envelopes.

\section{References}

1 Grimm LJ, Avery CS, Maxfield CM. Residency postinterview communications: more harm than good? J Grad Med Educ 2016;8 (01):7-9

2 Fellowship and Residency Electronic Interactive Database (FREIDA Online). Available at: http://www.ama-assn.org/go/freida. Accessed June 12, 2017

3 U.S. Census Bureau. Census Regions and Divisions of the United States. Available at: https://www2.census.gov/geo/pdfs/mapsdata/maps/reference/us_regdiv.pdf. Accessed February 2, 2018

4 ACGME. Accreditation Council for Graduate Medical Education (ACGME) - Public. Available at: https://apps.acgme.org/ads/Public. Accessed February 2, 2018

5 Jena AB, Arora VM, Hauer KE, et al. The prevalence and nature of postinterview communications between residency programs and applicants during the match. Acad Med 2012;87(10): 1434-1442

6 Nagarkar PA, Janis JE. Fixing the match: a survey of resident behaviors. Plast Reconstr Surg 2013;132(03):711-719

7 Miller JB, Schaad DC, Crittenden RA, Oriol NE, MacLaren C. Communication between programs and applicants during residency selection: effects of the match on medical students' professional development. Acad Med 2003;78(04):403-411

8 ACAPS Uniform Policy and Guidelines for Post Interview Communication. Available at: http://acaplasticsurgeons.org/multimedia/ files/ACAPS-Uniform-Policy-on-Post-Interview-Communication.ppt. Accessed June 10, 2017

9 Guidelines for Post-Interview Communication and Second Looks. Available at: http://www.im.org/p/cm/ld/fid=802. Accessed June 8, 2017

10 Chen AJ, Chan JJ, Scott IU, Greenberg PB. Ophthalmic resident education on preventable surgical errors. JAMA Ophthalmol 2013;131(09):1238-1240

11 Coombs PG, Feldman BH, Lauer AK, Paul Chan RV, Sun G. Global health training in ophthalmology residency programs. J Surg Educ 2015;72(04):e52-e59 